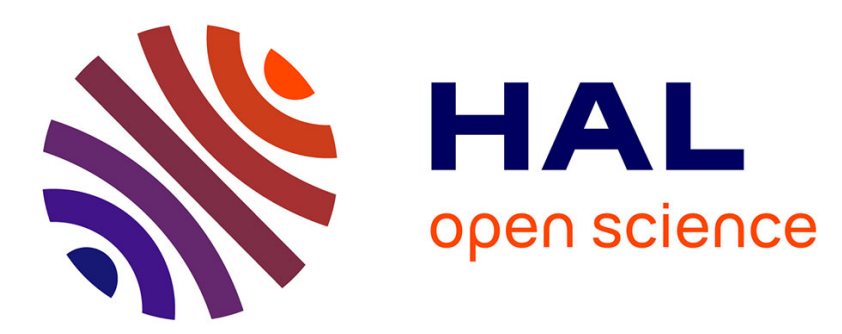

\title{
Quantitative assessment of intergranular damage due to PWR primary water exposure in structural Ni-based alloys
}

Benoît Ter-Ovanessian, Julien Deleume, Jean-Marc Cloué, Eric Andrieu

\section{- To cite this version:}

Benoît Ter-Ovanessian, Julien Deleume, Jean-Marc Cloué, Eric Andrieu. Quantitative assessment of intergranular damage due to PWR primary water exposure in structural Ni-based alloys. Corrosion Science, 2013, vol. 67, pp. 11-19. 10.1016/j.corsci.2012.09.048 . hal-00864144

\section{HAL Id: hal-00864144 https://hal.science/hal-00864144}

Submitted on 20 Sep 2013

HAL is a multi-disciplinary open access archive for the deposit and dissemination of scientific research documents, whether they are published or not. The documents may come from teaching and research institutions in France or abroad, or from public or private research centers.
L'archive ouverte pluridisciplinaire HAL, est destinée au dépôt et à la diffusion de documents scientifiques de niveau recherche, publiés ou non, émanant des établissements d'enseignement et de recherche français ou étrangers, des laboratoires publics ou privés. 


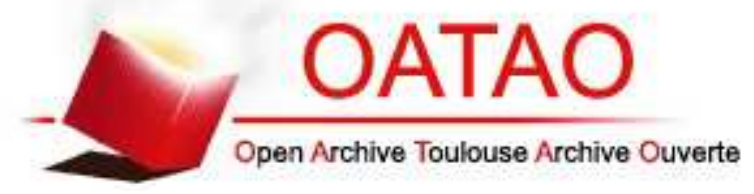

\section{Open Archive TOULOUSE Archive Ouverte (OATAO)}

OATAO is an open access repository that collects the work of Toulouse researchers and makes it freely available over the web where possible.

This is an author-deposited version published in : http://oatao.univ-toulouse.fr/ Eprints ID : 8786

To link to this article : DOI:10.1016/j.corsci.2012.09.048

URL : http://dx.doi.org/10.1016/j.corsci.2012.09.048

To cite this version : Ter-Ovanessian, Benoît and Deleume, Julien and Cloué, Jean-Marc and Andrieu, Eric. Quantitative assessment of intergranular damage due to PWR primary water exposure in structural Ni-based alloys. (2013) Corrosion Science, vol. 67 . pp. 11-19. ISSN 0010-938X

Any correspondance concerning this service should be sent to the repository administrator: staff-oatao@ listes-diff.inp-toulouse.fr 


\title{
Quantitative assessment of intergranular damage due to PWR primary water exposure in structural Ni-based alloys
}

\author{
Benoît Ter-Ovanessian $^{\mathrm{a}, *}$, Julien Deleume ${ }^{\mathrm{b}}$, Jean-Marc Cloué ${ }^{\mathrm{c}}$, Eric Andrieu ${ }^{\mathrm{d}}$ \\ ${ }^{a}$ MATEIS, INSA LYON, 7, Avenue Jean Capelle, 69621 Villeurbanne Cedex, France \\ ${ }^{\mathrm{b}}$ AREVA, Centre de recherche de CEZUS, Avenue Paul Girod, 73403 Ugine Cedex, France \\ ${ }^{\mathrm{c}}$ AREVA, AREVA NP 10, rue J. Récamier, 69456 Lyon Cedex 06, France \\ 'CIRIMAT, CNRS/UPS/INPT, ENSIACET, 4, allée Emile Monso, 31432 Toulouse Cedex 4, France
}

\begin{abstract}
A B S T R A C T
Two nickel-based alloys, alloy 718 and alloy 600, known to have different resistances to IGSCC, were exposed to a simulated PWR primary water environment at $360{ }^{\circ} \mathrm{C}$ for $1000 \mathrm{~h}$. The intergranular oxidation damage was analyzed in detail using an original approach involving two characterization methods (Incremental Mechanical Polishing/Microcopy procedure and SIMS imaging) which yielded a tomographic analysis of the damage. Intergranular oxygen/oxide penetrations occurred either as connected or isolated penetrations deep under the external oxide/substrate interface as far as $10 \mu \mathrm{m}$ for alloy 600 and only $4 \mu \mathrm{m}$ for alloy 718 . Therefore, assessing this damage precisely is essential to interpret IGSCC susceptibility.
\end{abstract}

Keywords:

A. Nickel

A. Alloy

C. Intergranular corrosion

C. Internal oxidation

C. Stress corrosion

B. SIMS

\section{Introduction}

The family of nickel-based alloys, widely used in the pressurized water reactors (PWR) of nuclear power plants is known to be sensitive to environmentally-induced intergranular stress corrosion cracking (IGSCC) [1-4]. Although numerous models have been proposed, the mechanisms that control IGSCC are still under debate [4-12]. The assumption that the oxidation process is at the origin of IGSCC initiation in nickel-based alloys appears likely [10-13]. Thus, the features of oxidation are assumed to make a major contribution to intergranular cracking. Their meticulous characterization is essential if their role is to be fully understood. Currently, numerous studies [14-24], essentially based on high resolution transmission electron microscopy (TEM) and scanning electron microscopy (SEM) have identified many of the characteristics of oxide film formation and damage occurring to the underlying metal. As a commonly accepted result, the oxide film is described as a double layer oxide - an inner $\mathrm{Cr}$-rich scale and an outer layer consisting of different complex crystallites (Ni, Fe...) - whose properties and characteristics differ according to the nature of the alloy exposed [14-18,22-25]. Moreover, the presence of a $\mathrm{Cr}$-depleted layer in the metal under the oxide/alloy interface and

\footnotetext{
* Corresponding author. Tel.: +334 724382 74; fax: +334 72438528

E-mail address: benoit.ter-ovanessian@insa-lyon.fr (B. Ter-Ovanessian).
}

the occurrence of intergranular attacks have also been described for different nickel-based alloys [13,15-21]. For years, the improvement of microscopy techniques (field emission gun scanning electron microscope, high-resolution transmission electron microscope, etc.) and associated chemical analysis have significantly improved the understanding of nickel-based alloy behavior. However, despite these reliable, relevant but qualitative characterizations, some aspects of IGSCC mechanisms, like the difference of susceptibility, still remain under question.

Recently, Secondary-Ion Mass Spectrometry (SIMS) examination of synthetic ternary $\mathrm{Fe}-\mathrm{Cr}-\mathrm{Ni}$ alloys $[26,27]$ showed that intergranular oxygen or oxide penetration disconnected from the conventional intergranular penetration may be observed far from the metal/oxide interface. This isolated intergranular oxygen may be involved in the damaging process. Therefore, taking certain precautions with the experimental setup and in the interpretation of the results, SIMS examination as a volume analysis method seems to provide new quantitative data. The present study aims to highlight the relevancy and the interest of two complementary methods, SIMS and an Incremental Mechanical Polishing/Microscopy (IMP/M) method, in order to fully and quantitatively characterize the intergranular damage to the base metal due to exposure. These characterizations were performed on two different nickelbased alloys used in nuclear power reactors, alloy 718 and alloy 600 which exhibit different susceptibilities to IGSCC. 


\section{Materials and experimental procedures}

\subsection{Materials and corrosion testing}

Two different industrial alloys were studied, alloy 718 and alloy 600 . The chemical composition of the alloys is given in Table 1 .

Coupons of alloy 718 were machined from a nuclear grade plate. Specimens were then heat treated as follows: solution annealing at $1050^{\circ} \mathrm{C}$ for $1 \mathrm{~h}$ followed by air quenching then the conventional aeronautic heat treatment in an argon atmosphere: hold at $720^{\circ} \mathrm{C}-8 \mathrm{~h}$, cooling $50^{\circ} \mathrm{C} / \mathrm{h}$ down to $620^{\circ} \mathrm{C}$, hold at $620^{\circ} \mathrm{C}-8 \mathrm{~h}$ and final air cooling to room temperature. The microstructure was characterized by equiaxed and fully recrystallized small grains (ASTM grain size number $=8-9$ ) with random grain boundaries and by the presence of rows of $\mathrm{Nb} / \mathrm{Ti}$ carbide.

Coupons of alloy 600 were extracted from a mill-annealed square plate $\left(980^{\circ} \mathrm{C} / 4 \mathrm{~min}+\right.$ cooling under hydrogen atmosphere) and then heat treated in an inert atmosphere for $2 \mathrm{~h}$ at $820^{\circ} \mathrm{C}$. The microstructure was characterized by a heterogeneous grain size (ASTM grain size number from 4-10). No intragranular carbide precipitation but only intergranular chromium carbides $\mathrm{Cr}_{7} \mathrm{C}_{3}$ (grain boundary coverage $>92 \%$ ) were observed. This intergranular precipitation is known to induce a sensitization of the alloy to intergranular oxidation due to the formation of a $\mathrm{Cr}$-depleted area at the vicinity of the carbides. However, such microstructure is commonly assumed to be the more resistant to SCC [28].

Two surface states were initially studied for both materials. Some coupons were mechanically polished using SiC papers and diamond paste down to $1 \mu \mathrm{m}$ (mirror aspect). The others were only grinded down to $\mathrm{SiC}$ paper grade 1200 . During and after these preparation steps, the coupons were ultrasonically cleaned in acetone, ethanol and pure water.

Then, corrosion tests were performed on the coupons in a static autoclave at $360^{\circ} \mathrm{C}$ and under a pressure of 165 bar for $1000 \mathrm{~h}$. The simulated nominal PWR primary environment used during the test was composed of deionised water containing $1200 \mathrm{ppm} \mathrm{B}$ (weight) as boric acid $\left(\mathrm{H}_{3} \mathrm{BO}_{3}\right)$ and $2 \mathrm{ppm} \mathrm{Li} \mathrm{(weight)} \mathrm{as} \mathrm{lithium} \mathrm{hydroxide}$ ( $\mathrm{LiOH}$ ). Deaeration of the medium was obtained by argon bubbling in the autoclave for at least one night. The partial pressure of hydrogen was adjusted to 0.3 bar and was continuously monitored with a Pd-Ag membrane.

\subsection{Microscopy and Incremental Mechanical Polishing experiments}

The corrosion products were characterized using a field emission gun scanning electron microscope (FEG-SEM) LEO 1530 operating at voltages from $100 \mathrm{~V}$ to $30 \mathrm{kV}$ and fitted with an energy dispersive X-ray spectroscopy (EDX) system for chemical analysis to determine the nature and the morphology of the oxide film. FEG-SEM observations were performed on oxidized surface and on cross-section for each material.

Then, to determine the occurrence and the depth of intergranular oxidation, coupons from each of the exposed alloys were investigated using the IMP/M method. Observations with an optical microscope $(\mathrm{OM})$ were performed after several polishing steps using a colloidal silica suspension (OP-S Suspension ${ }^{\mathrm{TM}}$ Struers) or $1 \mu \mathrm{m}$-diamond paste. For each polishing step, abrasion depth was determined by measuring the reduction of the diagonal length

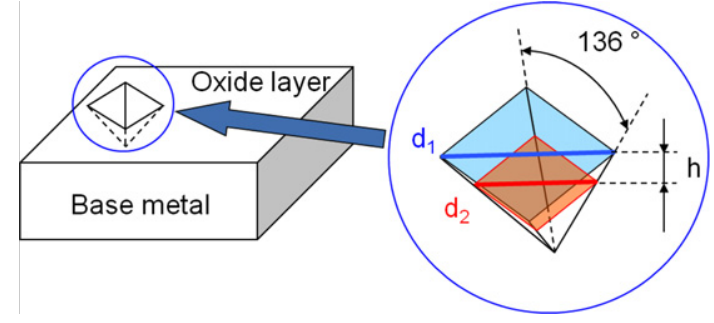

Fig. 1. Estimation of the abrasion depth during the IMP/M procedure.

(Fig. 1) of four $\mathrm{HV}_{1000 / 15 s}$ hardness indentations arranged in a $1 \mathrm{~cm}$ square, around the analyzed zone. After each polishing step, the abrasion depth may be estimated as followed:

$$
h=\frac{d_{1}-d_{2}}{2 * \sqrt{2} * \tan \frac{136}{2}}
$$

where $d_{1}$ and $d_{2}$ are respectively, the initial diagonal length and the diagonal length at the considered step. With this method, the abrasion step is controlled by the time of each polishing step and the abrading product. In this study an abrasion step of about $0.3 \mu \mathrm{m}$ was used. This process was repeated on three different zones for both materials in order to assess: the thickness of the oxide scale, the depth of the metal affected by intergranular oxidation and the distribution of intergranular damage. In order to be representative of the material, each analyzed zone includes a least 50 grains (about $200 \times 200 \mu \mathrm{m}$ for alloy 718 and $600 \times 600 \mu \mathrm{m}$ for alloy 600 ). However, it is important to note that even though this technique gives coherent results, it is limited by the lateral resolution of the microscope: $0.2 \mu \mathrm{m}$.

\subsection{Secondary Ion Mass Spectroscopy (SIMS) experiments}

SIMS analyses were carried out on a CAMECA IMS $4 \mathrm{~F} / 6 \mathrm{~F}$ instrument at ten different locations on both materials. Abrasion profile mode and Resistive Anode Encoder (RAE) mode were used to determine local chemical composition and chemical distribution with an analyzed zone diameter of $30 \mu \mathrm{m}$ for a total area of the abrasion zone of $150 \times 150 \mu \mathrm{m}^{2}$. The abrasion profile mode was used in order to get an average response of the chemical composition for the analyzed zone during sequential abrasion (depth resolution of $2 \mathrm{~nm}$ ). The RAE mode provides 2D-elemental maps for oxygen and the main constitutive metallic elements of the alloy $(\mathrm{Ni}, \mathrm{Fe}, \mathrm{Cr} \ldots$ ) during the abrasion process with a lateral resolution of $0.2 \mu \mathrm{m}$. For both modes, the abrasion current was held at $10 \mathrm{nA}$ and a $\mathrm{Cs}^{+}$source $(10 \mathrm{keV})$ was used for bombardment. These parameters were validated during a preliminary study using optical interferometry to measure the depths of abrasion craters obtained for three different abrasion times [25]. The abrasion rate in nickel-based alloys was quantified to be $3.5 \mathrm{~nm} / \mathrm{s}$. Consequently, the data collected to build elemental maps can be plotted versus time and/or depth. $\mathrm{Cs}^{+}$ions were used in order to reduce the "matrix effect". In fact, for metal element M, the intensity of the collected secondary ion signal $\mathrm{M}^{+}$is strongly influenced by all other metallic cations with frequent aberration phenomena. It is no longer a problem if $\mathrm{CsM}^{+}$or $\mathrm{CsMO}^{+}$are the species collected.

Table 1

Chemical composition of alloys studied [weight \%].

\begin{tabular}{|c|c|c|c|c|c|c|c|c|c|c|c|c|c|}
\hline & ASTM & $\mathrm{Al}$ & C & Co & $\mathrm{Cr}$ & $\mathrm{Cu}$ & $\mathrm{Fe}$ & $\mathrm{Mn}$ & Mo & $\mathrm{Ni}$ & $\mathrm{Nb}+\mathrm{Ta}$ & $\mathrm{Si}$ & $\mathrm{Ti}$ \\
\hline 718 & $8-9$ & 0.48 & 0.034 & 0.022 & 18.3 & 0.009 & Bal. & 0.046 & 3.04 & 53.69 & 5.17 & 0.031 & 1.05 \\
\hline 600 & $4-10$ & 0.24 & 0.058 & - & 16.1 & 0.02 & Bal. & 0.8 & - & 73.8 & - & 0.45 & 0.29 \\
\hline
\end{tabular}


Moreover, with such abrasion parameters, preferential milling may be observed at grain boundaries. It may significantly affect the measurement accuracy. In order to limit this detrimental effect, the thickness of the SIMS samples was between 10 or $15 \mu \mathrm{m}$. The occurrence of preferential milling is discussed in the discussion part.

Finally, in order to avoid the influence of oxide scale roughness on the determination of the metal/oxide interface location and to keep the highest sensitivity for crucial elements, SIMS analyses were performed by starting abrasion from the alloy underlying the oxide scale ("Backside mode"), rather than from the oxide scale to the base metal in direct mode. For this purpose specific specimen preparation was carried out according to a previously published procedure $[15,25,29]$.

It is worth noting that "Backside mode" SIMS chemical analyses were carried out on both alloys before and after exposure to simulated primary water in order to differentiate exposure consequences from process consequences.

\section{Results}

\subsection{SEM observations}

SEM examinations showed that the oxides formed in primary PWR water were quite similar for both alloys and for both surface preparations, although minor differences in terms of sizes and distributions did occur. The oxides were found to be separated into two layers: an outer scale made of a sparse distribution of varied crystallites and a compact and continuous inner scale. For the outer scale, two populations of crystallites were identified according to their size. One was composed of small crystallites covering most of the surface: for alloy 718 , the size was essentially in the range 50-100 nm (Fig. 2a) while, for alloy 600, it was $20-50 \mathrm{~nm}$ (Fig. 2b). The second population contained larger crystallites
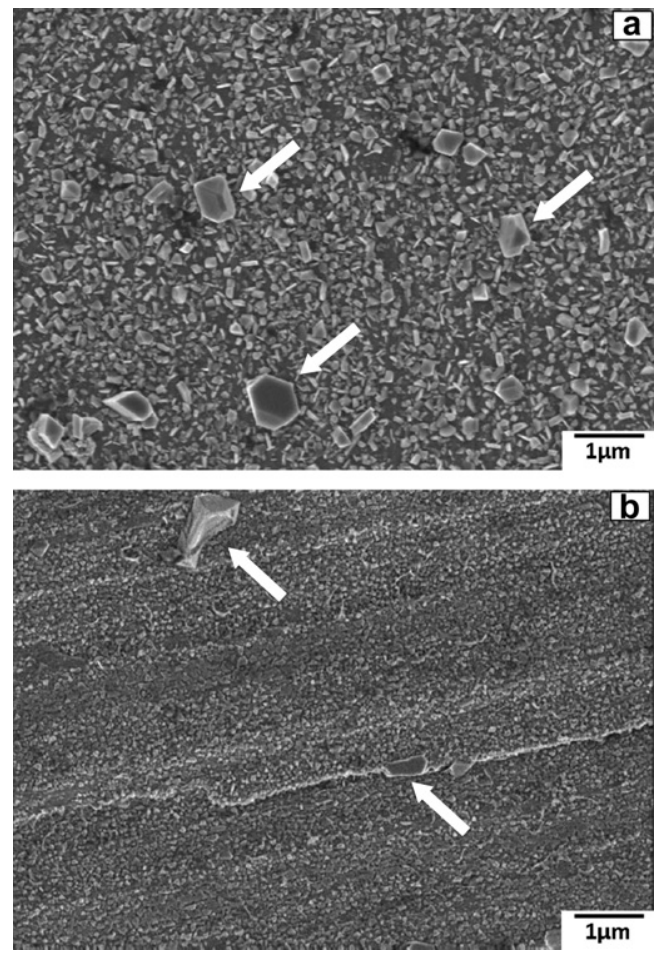

Fig. 2. FEG-SEM observations of the oxide film formed during $1000 \mathrm{~h}$-exposure to simulated primary water at $360^{\circ} \mathrm{C}$ on (a) alloy 718 (mirror aspect surface) and (b) alloy 600 (1200 SiC surface). ranging from $500 \mathrm{~nm}$ to 1 or $2 \mu \mathrm{m}$ (white arrows in Fig. 2a and b). By EDX analysis performed on cross section specimens, chemical differentiation between the two families is not straightforward even if qualitatively, it seems that the smaller precipitates were richer in $\mathrm{Cr}$ than the bigger ones. The general chemical formula of these two families of crystallites is, as already assumed, $\left(\mathrm{Ni}_{1-x} \mathrm{Fe}_{x}\right)\left(\mathrm{Fe}_{1-y} \mathrm{Cr}_{y}\right)_{2} \mathrm{O}_{4}$ with $\mathrm{y}$ close to 0 [13-18,22-25]. These crystallites seem to be embedded in another oxide layer made of small $\mathrm{Cr}$-rich oxide grains [13-18,22-25]. This inner layer is composed of $\mathrm{Cr}_{2} \mathrm{O}_{3}$ and some $\mathrm{Cr}$-rich spinels for an oxide film thickness commonly assumed to be less than $50 \mathrm{~nm}$ for alloy $718[25,30]$ and $100 \mathrm{~nm}$ for alloy 600 [14-16,22-24]. A further study by TEM crosssection seems to be required to describe the whole structure and composition of these oxides precisely.

\subsection{Incremental Mechanical Polishing/Microscopy results}

As first results, the different methods used in this work do not show any influence of the surface preparation on the intergranular oxidation behavior. In the following parts relative to intergranular oxidation, only results obtained on specimen polished at $1 \mu \mathrm{m}$-diamond paste before exposure are presented.

In order to investigate the intergranular oxidation occurring during the exposure, the oxide layer was gently removed by mechanical polishing. When the metal appeared, almost all of the grain boundaries exhibited corrosion products. The deeper the abrasion, the less the grain boundaries were found to be affected by intergranular oxidation. Polishing was performed until only unaffected metal was detected. Fig. 3 illustrates the intergranular oxidation behavior of alloy 718 after primary water exposure, as revealed by the IMP/M method. Schematic sizes of the Vickers hardness indentations are reported to indicate the link between the optical micrographs and the depth. Intergranular oxidation was observed beneath the top of the oxide layer to a depth of $1.4,2.3$ and $3.8 \mu \mathrm{m}$ for alloy 718 and $2.8,3.9,4.2 \mu \mathrm{m}$ for alloy 600. The oxide film thickness was estimated to be about $1.1 \pm 0.3 \mu \mathrm{m}$ for both alloys. In their works, Panter et al. $[15,16]$ proved that triple lines are deeper affected by oxidation than grain boundaries. Consequently, black spots observed on the last optical micrograph on Fig. 3 might be triple lines. However, SEM or TEM examinations are required to confirm this assumption.

\subsection{SIMS results and $3 D$ RAE representation}

In order to go further into the identification of intergranular oxidation behavior, chemical analyses on ten different locations for both exposed materials were carried out by "backside mode" SIMS. Representative SIMS profiles for non-exposed alloys and for exposed alloys are shown respectively in Fig. 4 and Fig. 5. In addition to oxygen and oxide signals, carbon and silicon signals were collected to determine the presence of carbides and to show the end of the experiment ( $\mathrm{Si}$ support plate).

The profiles on Fig. 4 show that the different signals remain at an average value, except the carbon signal indicating the presence of carbide in the analyzed volume (Fig. 4a). The average value of the carbon signal is higher for alloy 600 (Fig. 4b) than for alloy 718 (Fig. 4a), probably due to the presence of numerous intergranular carbides in alloy 600 . The Si signal was the first signal to increase and the analysis was stopped when it was significantly detected.

The shape of the curves in Fig. 5 is characteristic of the behavior of intergranular oxidized alloys. During metal abrasion, the different signals reached the average values of the non-exposed alloys. Then, close to the metal/oxide interface, oxygen and oxide signals rapidly increased. Moreover, it is important to note that the abrading rate and efficiency became different when the abrasion started 
depth $=0.3 \mu \mathrm{m}$

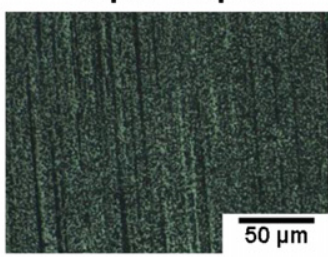

depth=1.5 $\mu \mathrm{m}$

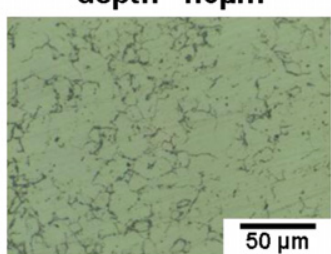

depth=2.1 $\mu \mathrm{m}$

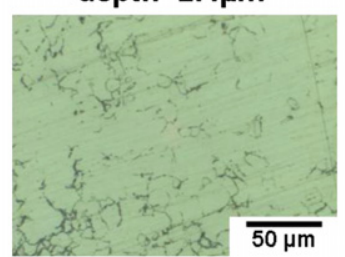

depth=3.3pm

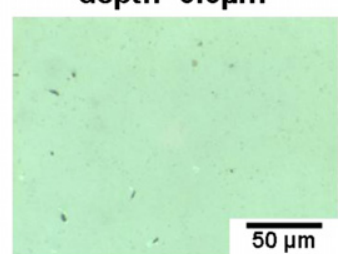

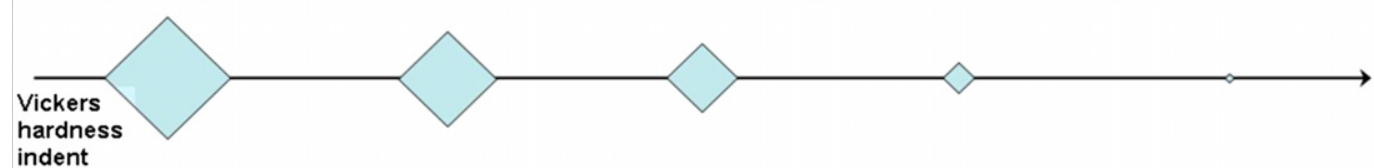

Fig. 3. Estimation of intergranular oxidation distribution and depth by incremental mechanical polishing/microscopy methods on exposed alloy 718 .

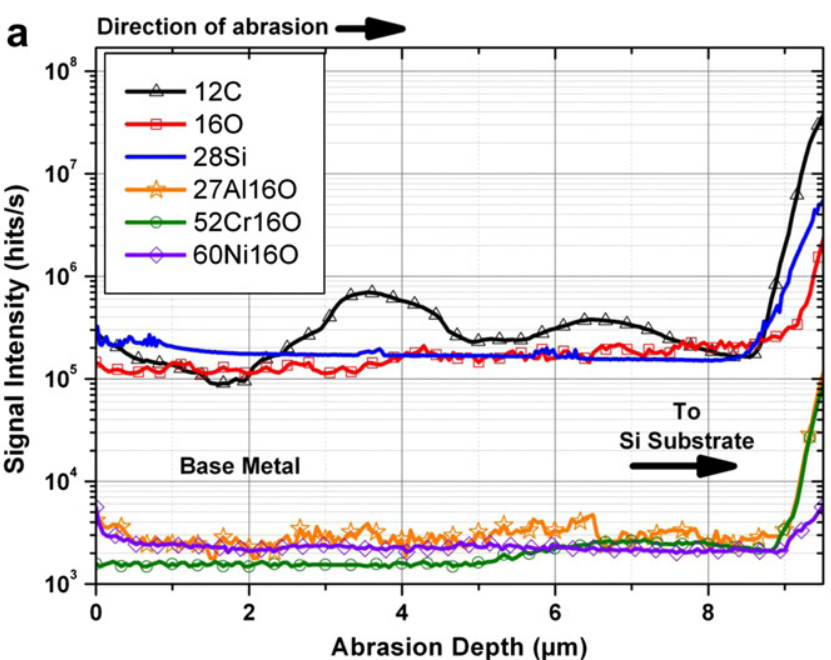

b

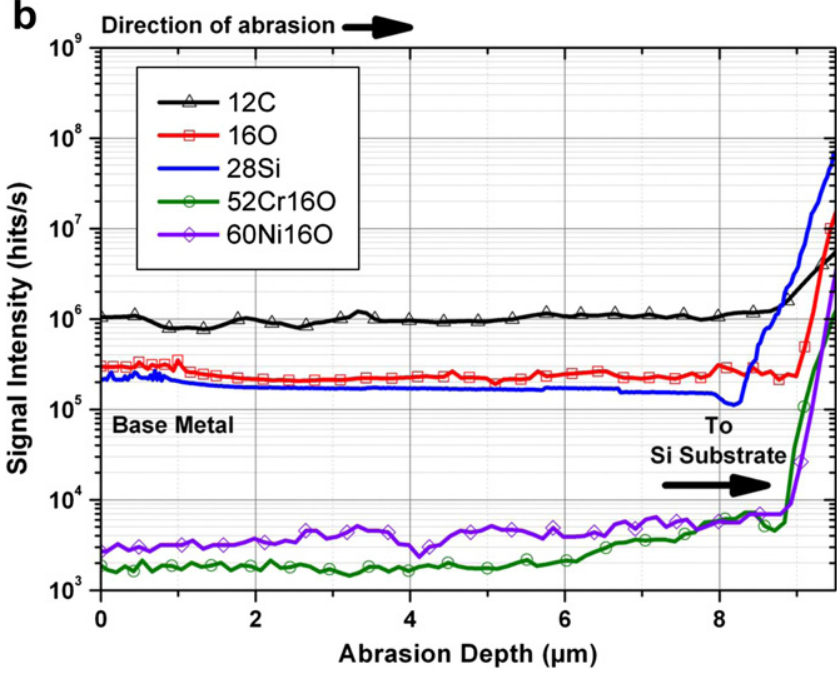

Fig. 4. Representative SIMS profiles obtained on a coupon of alloy 718 (a) and on a coupon of alloy 600 (b) before exposure to simulated primary water.

in the oxide layer, implying the variation of other signals such as that of $C$

For exposed alloy 718, the oxygen signal increased from 6.4 to $9 \mu \mathrm{m}$, while the surface of the system was detected at $9 \mu \mathrm{m}$ (Fig. 5a). This depth of $2.6 \mu \mathrm{m}$ may be associated to an affected area characterizing both the oxide films and the presence of intergranular oxide penetration. From the RAE experiments the thickness of the oxide film was distinguished from the depth affected by oxide penetration. For example, 2D basic maps of $\mathrm{Cr}$ oxide, collected by RAE experiments, dissociate the depths affected by the two phenomena (Fig. 5a): the intergranular penetration from 6.4 to $7.8 \mu \mathrm{m}$ and the oxide film from 7.8 to $9 \mu \mathrm{m}$. For alloy 600 (Fig. $5 \mathrm{~b}$ ), the $\mathrm{O}$ and the $\mathrm{Cr}$ oxide signal indicate also the presence of deep oxide under the metal/oxide interface, which may be interpreted as the oxidation of the intergranular chromium carbides during exposure. Intergranular preferential milling can be also considered for the interpretation of the increase close to the interface. The presence of such oxidized carbides or oxygen nodules are not detected in the non-exposed material (Fig. 4b).

From all the SIMS analysis in profile mode, the depth affected by intergranular oxidation was estimated at $2.7 \pm 0.5 \mu \mathrm{m}$ for alloy 718 and $3.7 \pm 0.7 \mu \mathrm{m}$ for alloy 600 , while the oxide film thickness was $1.2 \pm 0.2 \mu \mathrm{m}$ for alloy 718 and $1.0 \pm 0.2 \mu \mathrm{m}$ for alloy 600 . The SIMS profile mode and IMP/M were concordant.

Furthermore, SIMS instrumentation and software enabled the 2D RAE elemental maps to be stacked and reprocessed into a 3D representation of the analyzed volume. The 0 map reconstruction of experiments made on alloy 718 and 600 are reported below (Figs. 6a and 7a and 8). Moreover from these 3D representations corresponding to sequential 2D elemental maps, it is possible to generate SIMS profiles on selected areas. Indeed, if only the stacking of the 2D 0 map is presented in Figs. $6 \mathrm{a}$ and $7 \mathrm{a}$ and 8, all the abrasion sequence in terms of chemical species is performed and recorded during the analysis. Therefore, a profile of analyzed elements can be extract with a good accuracy from delimited zone of the 3D representation.

While the 3D representation of exposed alloy 718 clearly demonstrated the occurrence of intergranular penetrations connected to the oxide film, alloy 600 also presented oxygen nodules which appear to be isolated from the oxide film (Figs. 6a and 7a and 8). From the 3D SIMS tomography (Figs. 6a and 7a), SIMS profiles of selected areas was extracted: profile a for alloy 718 (Fig. 6b) and profile b for alloy 600 (Fig. 7b). Both of these profiles highlight particular features of the corrosion process. In profile a (Fig. 6b), the first ionic signal to significantly increase is identified as oxygen alone without any correlation with other signals. Oxygen penetration reached $380 \mathrm{~nm}$ beneath the oxide that was the most stable and consequently closest to the metal i.e. aluminium oxide for alloy 718 [30]. Profile b (Fig. 7b), which is focused on the oxygen nodule, illustrates that, with the technique presently used, the nodule seems to be disconnected laterally and in depth from the oxide film and from oxide penetration. Indeed, the $O$ signal reaches its average value between the nodule and the interface. For this nodule, the $O$ signal is not correlated with the signals of the other elements. In Fig. 8, the oxygen nodule is even deeper detected. In alloy 600 , such oxygen and sometimes oxide nodules have been detected up to $10 \mu \mathrm{m}$ beneath the metal/oxide film interface. Analyses 

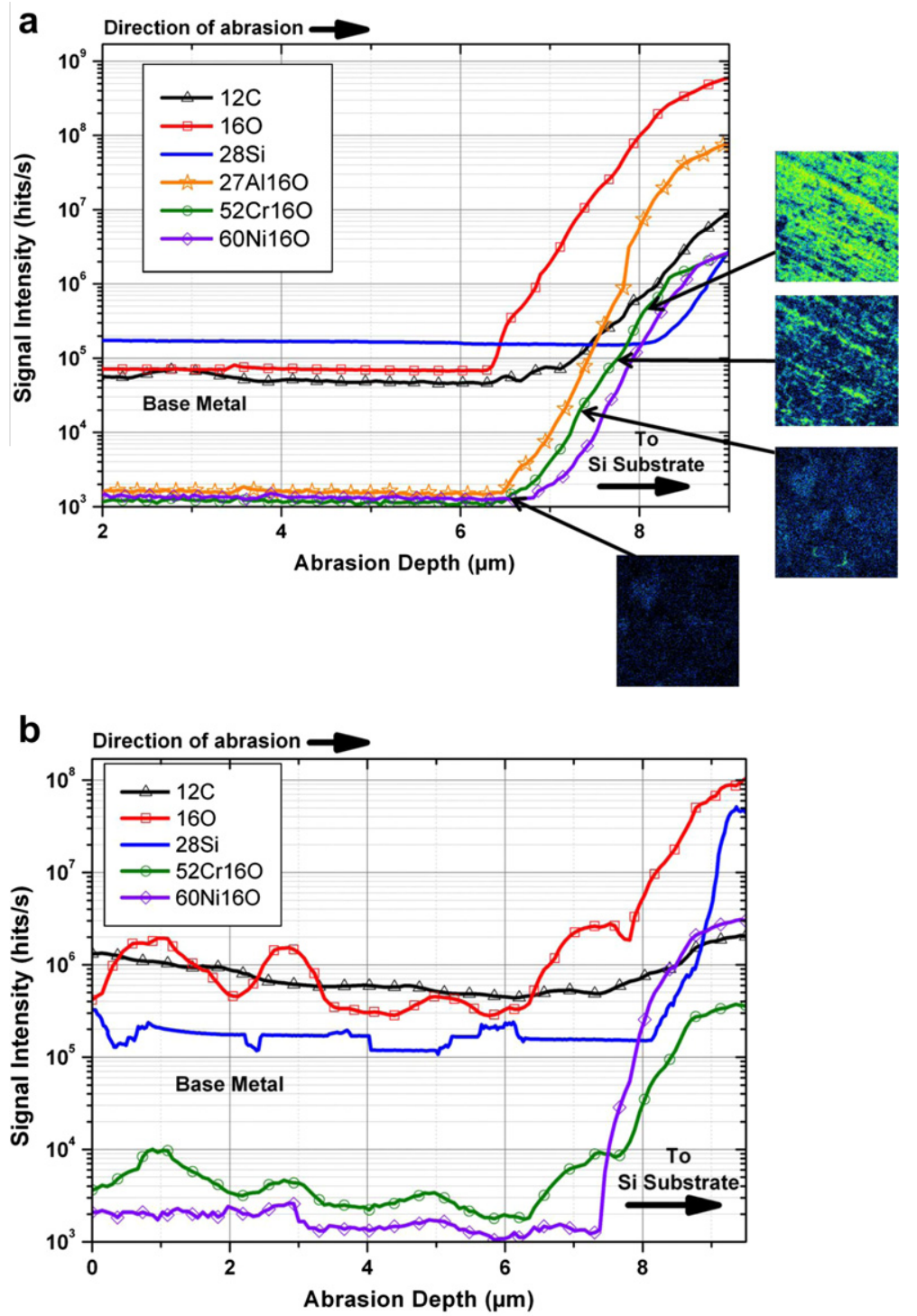

Fig. 5. Representative SIMS profiles obtained on a coupon of alloy 718 (a) and on a coupon of alloy 600 (b) after exposure to simulated primary water for $1000 \mathrm{~h}$ at $360{ }^{\circ} \mathrm{C}$. Intergranular penetration was distinguished from oxide film using the RAE 52Cr160 elemental maps (a).

performed in RAE mode on alloy 600 before exposure to primary water confirm the result presented in Fig. $4 \mathrm{~b}$ indicating that the phenomenon is a direct consequence of exposure. Conversely, in alloy 718 they have never been observed.

\section{Discussion}

The main findings of the present study concern the identification and quantification of the intergranular damage resulting from primary water exposure using two complementary methods: IMP/ $\mathrm{M}$ and SIMS. The overall experimental data is summarized in Table 2 . The average values, as well as the min and the max values obtained from all the experiments are reported.

Both alloys exhibited intergranular oxide penetration of up to a few micrometers connected to and beneath the metal/oxide film interface. By cross-section TEM or SEM observations, several different authors have already shown the presence of oxygen in grain boundaries in the underlying metal on nickel-based alloys [13,15-21]. EDX chemical analyses, carried out on these penetra- tions, show that they are mainly composed of chromium oxide $\mathrm{Cr}_{2} \mathrm{O}_{3}$ and that their formation is correlated to $\mathrm{Cr}$-depletion and Ni-enrichment of the surrounding matrix [19-21]. Furthermore, principally investigating on alloy 600 or alloy 690, TEM observations demonstrate that oxygen penetrates most grain boundaries for annealed material and also deformation bands for coldworked materials. Panter et al. $[15,16]$ reported that the penetration of oxide is much deeper in triple grain boundaries. Overall, these works indicate the existence of numerous parameters such as the nature or reactivity of the grain boundaries influencing distribution and depth of penetration. However, the techniques generally used remain local and/or only provide a $2 \mathrm{D}$ representation of the polycrystal. Studying each parameter and providing statistical data implies heavy investment in terms of cost and time. In contrast, the IMP/M methods used in the presents study were very useful to complete the data: it considers the depth affected by intergranular oxidation of a representative volume analyzed (about $200 \times 200 \times 10 \mu \mathrm{m}$ for alloy 718 ) and may indicate how the distribution of grain boundaries affected by the oxidation varies with depth. Moreover, even though the information given by 

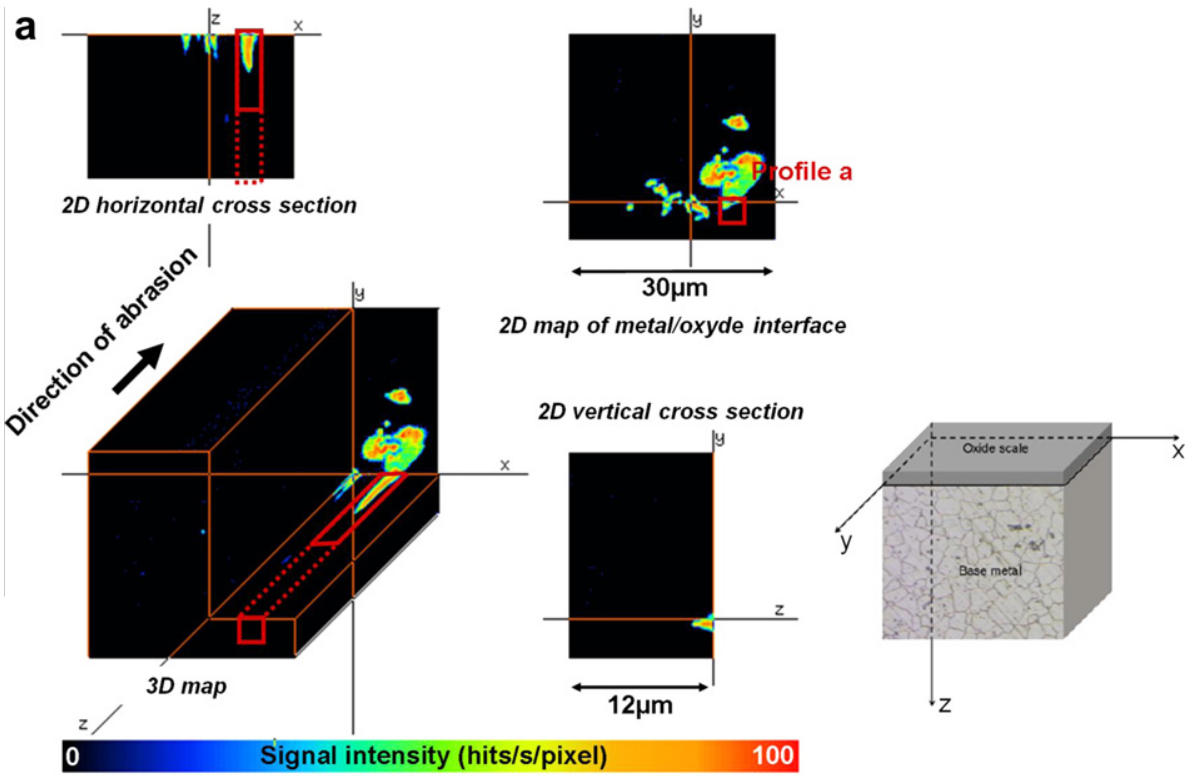

b

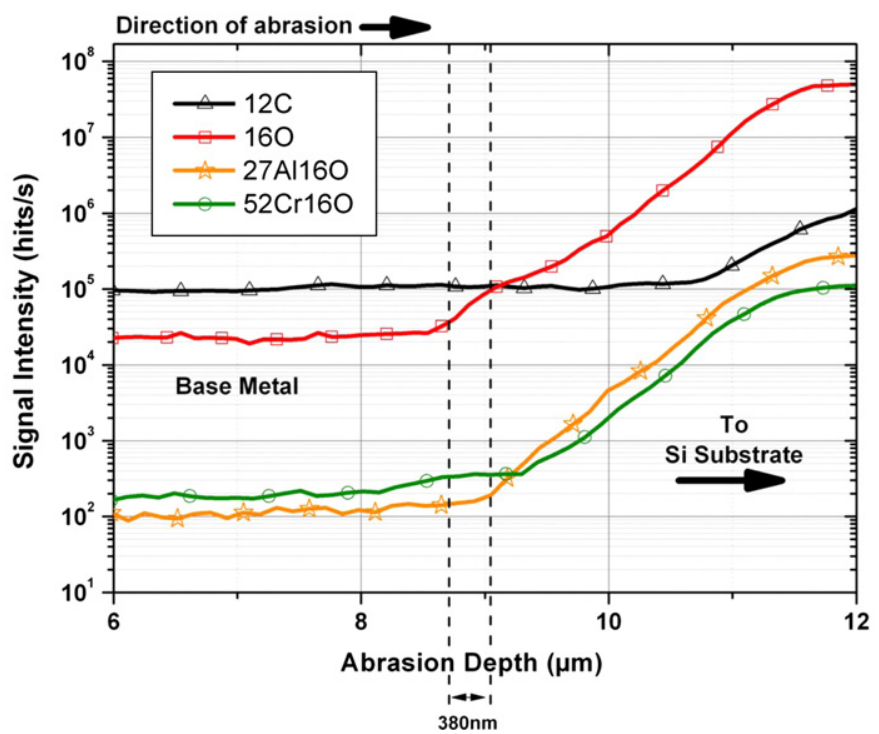

Fig. 6. Example of a 3D computed RAE map for normalized oxygen signal after SIMS analysis on exposed alloy 718 (a) and reprocessed SIMS profiles on selected volume profile a- (b).

IMP/M methods here was only statistical, Incremental Mechanical Polishing can be associated in the future with SEM observations and with EDX mapping to provide information on grain boundaries oxidation or with EBSD to provide information on the texture and on grain boundaries orientation. To go further, IMP/M methods may also be complemented by sequential sectioning methods (FIB 3D slicing) which may characterize intergranular penetration with nm-resolution on selected areas [31].

For both alloys exposed here, almost all the grain boundaries were affected by oxidation which means that there was no preferential attack. Moreover, the maximal depth affected by intergranular oxidation was similar for both materials (see Table 2) which means firstly that the chemical difference between the two alloys is not the main point governing the process and secondly that the difference of IGSCC behavior is not directly connected to this phenomenon. Another finding revealed in this study is that the depth affected, as determined by IMP/M, was in full agreement with the depth affected as determined by "backside" SIMS analyses. This result implies that preferential milling occurring during the SIMS abrasion doesn't significantly affect the interpretation of the "backside" SIMS measurement.

In addition to detecting intergranular damage, SIMS provides other important data. Firstly, as Deleume already observed for alloy 718 [30], the first increasing oxide signal in the vicinity of the oxide film or intergranular penetration, is aluminium oxide. From a thermodynamic point of view, this suggests that Al participates in the formation of the oxide film in such conditions. Nevertheless, the nature and the character of this participation are not clearly identified presently. For example, aluminium oxide has not yet been detected by TEM examinations.

Secondly, SIMS provides evidence of the presence of oxygen at the tip of some intergranular penetration in alloy 718. Actually, the presence of such enrichment has already been observed in different nickel-based alloys by Guerre et al. [32], Laghoutaris [33] and Deleume $[26,27]$ using the same techniques. Working on alloy 600 exposed in simulated primary water containing 
a
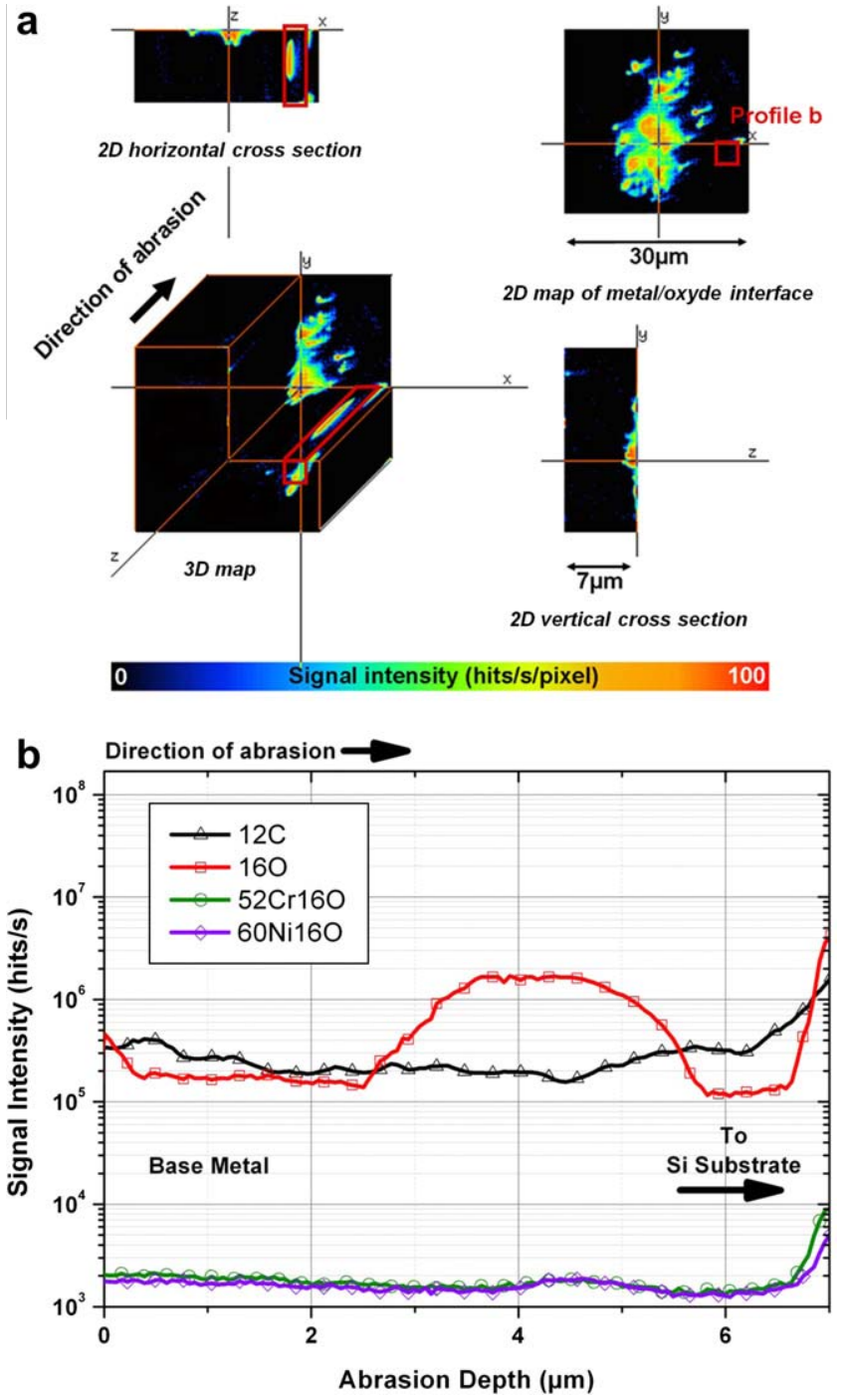

Fig. 7. Example of a 3D computed RAE map for normalized oxygen signal after SIMS analysis on exposed alloy 600 (a) and reprocessed SIMS profiles on selected volume -profile b- (b).

isotopic marker $\left(\mathrm{O}^{18}\right)$, Guerre et al. [32] or Laghoutaris [33] proved that the oxygen observed at the penetration tip comes from the exposure to the environment and not from the material itself. As yet, the nature (state, bindings...) of the oxygen segregated at the penetration tip has not been identified and is assumed by Deleume to be "free" [26,27]. It could be the oxygen activity at the penetration tip does not allow the formation of an oxide.

Thirdly, other intergranular damage, not usually observed by other methods, was observed by SIMS analysis. Indeed, oxides/ oxygen nodules deep inside exposed alloy 600 are detected during RAE mode experiments. SIMS analysis of non-exposed alloy indicates that these are a consequence of exposure. In their work on alloy 600, Guerre et al. [32] show also the existence of deep nodules isolated laterally and in depth by SIMS methods, but don't evidence them by TEM investigations. The lateral resolution of SIMS RAE mode $(0.2 \mu \mathrm{m})$ does not allow us to maintain that those nodules are totally disconnected. It seems possible that a non-detectable with SIMS techniques very thin intergranular oxide binds such nodules to the metal/oxide interface. However, the detection of such nodules at different location and for differ-

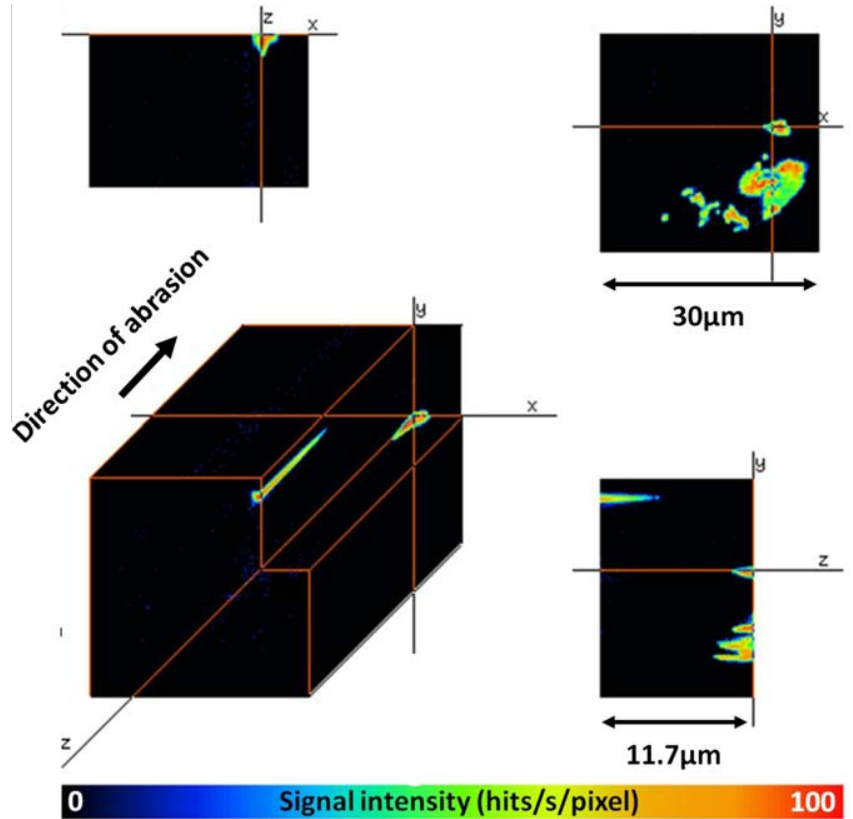

Fig. 8. Another example of a 3D computed RAE map for normalized oxygen signal after SIMS analysis on exposed alloy 600 showing intergranular oxides connected and disconnected from the metal/oxide interface.

ent depth implies that further investigations are required with other tomographic methods (X-ray tomography, Atom probe tomography...) in order to validate precisely this phenomenon. Indeed, the presented IMP/M method describes accurately the connected intergranular oxidation but does not evidence such nodules.

Moreover, the depth at which these intergranular nodules occur implies transport of the oxygen in disagreement with conventional transport mechanisms, such as diffusion transport, at this temperature. As a continuous protective $\mathrm{Cr}_{2} \mathrm{O}_{3}$ oxide layer forms rapidly on both materials, oxygen penetration is assumed to occur only during the very first steps of oxidation. As few reports mention this internal oxidation in primary water, the formation of such intergranular nodules remains difficult to explain. An accelerated diffusion process due to the presence of numerous dislocations, or induced by vacancies and oxygen synergic migrations remains under question. Complementary characterisations are still required to understand the mechanisms involved.

However, whatever the mechanism, the intergranular oxide penetrations -connected or isolated- have to be considered as a key parameter concerning the environment/material interactions occurring in the IGSCC process. Oxygen or oxide observed in almost all nickel-based alloys exposed to primary water is known to be detrimental for grain boundary cohesion [10-12,34,35]. This embrittlement of the grain boundaries may be assumed to promote the degradation process. Consequently, assessment of the oxidation-affected depth should cover all the features of the corrosion process as a whole as well as each feature separately in order to determine the difference of IGSCC susceptibility of exposed nickel-based alloys. The present study shows that both materials are susceptible to intergranular oxide penetration linked to the metal/oxide film interface (affected depth about 1-4 $\mu \mathrm{m}$ ), but also that only alloy 600 is affected by isolated intergranular oxide. Yet, alloy 600 is known to be more sensitive to IGSCC than alloy 718. Actually, the fact that alloy 718 is not affected by isolated intergranular oxide may be a key point to understand its higher resistance. 
Table 2

Consequences of primary water exposure on alloys 718 and 600 as characterized by different methods (Average values \pm standard deviations and (min-max) values).

\begin{tabular}{|c|c|c|c|}
\hline \multirow[t]{2}{*}{ SEM } & \multirow[t]{2}{*}{ Oxide film nature } & 718 & 600 \\
\hline & & \multicolumn{2}{|c|}{$\begin{array}{l}\text { External layer }(<1.5 \mu \mathrm{m}):\left(\mathrm{Ni}_{1-x} \mathrm{Fe}_{x}\right)\left(\mathrm{Fe}_{1-y} \mathrm{Cr}_{y}\right)_{2} \mathrm{O}_{4} \\
\text { Internal layer }(<100 \mathrm{~nm}): \mathrm{Cr}_{2} \mathrm{O}_{3} / \mathrm{Ni}_{x} \mathrm{Fe}_{1-x} \mathrm{Cr}_{2} \mathrm{O}_{4}[13-18]\end{array}$} \\
\hline IMP/M (3 locations) & $\begin{array}{l}\text { Estimated thickness of oxide film }(\mu \mathrm{m}) \\
\text { Depth affected by intergranular connected penetrations }(\mu \mathrm{m})\end{array}$ & $\begin{array}{l}1.1 \pm 0.3(0.8-1.4) \\
2.5 \pm 1.2(1.2-3.8)\end{array}$ & $\begin{array}{l}1.1 \pm 0.3(0.8-1.4) \\
3.6 \pm 0.7(2.8-4.2)\end{array}$ \\
\hline SIMS (10 analyses) & $\begin{array}{l}\text { Thickness of oxide film }(\mu \mathrm{m}) \\
\text { Depth affected by intergranular connected penetrations }(\mu \mathrm{m}) \\
\text { Maximum depth affected by oxidation }(\mu \mathrm{m})^{*}\end{array}$ & $\begin{array}{l}1.2 \pm 0.2(1-1.5) \\
2.7 \pm 0.9(1.4-4) \\
2.7 \pm 1.2(1.4-4)\end{array}$ & $\begin{array}{l}1.0 \pm 0.2(0.8-1.2) \\
3.7 \pm 0.7(2.4-5) \\
7.7 \pm 2.5(5-10) \\
\text { Internal oxide penetrations }\end{array}$ \\
\hline
\end{tabular}

The maximum depth affected by oxidation includes the depth affected by intergranular connected oxides/oxygen penetrations and the depth affected by intergranular isolated oxides/oxygen penetrations.

\section{Conclusion}

The consequences of exposure to simulated PWR primary water at $360{ }^{\circ} \mathrm{C}$ for $1000 \mathrm{~h}$, especially in terms of intergranular damage were characterized by different straightforward methods on alloy 600 and alloy 718. The accuracy and reproducibility of IMP/M and SIMS, enabled oxidation to be quantified and yielded some interesting new information.

For the materials studied, it was mainly shown that penetration of oxygen under the oxide scale occurred during primary water exposure and that the penetration may be observed and quantified. It was also shown that the behavior of both alloys differs in terms of depth of damaging but also in terms of the nature of the damage. Indeed, oxygen penetration was observed as far as $10 \mu \mathrm{m}$ from the oxidized surface for alloy 600 and $4 \mu \mathrm{m}$ for alloy 718 . Finally, as exposure in primary water involves micro-scale and nano-scale consequences on the IGSCC process, advanced characterization techniques are required to provide reliable and relevant information. Therefore the association of different techniques such as TEM, FEG-SEM, SIMS, IMP/M, 3D atom probe ... is needed to obtain an in-depth and statistically valid characterization of the consequences of primary water induced corrosion. Such a quantitative description providing exhaustive experimental facts is essential to improve the understanding of materials/environment interactions and to assess the occurrence of SCC processes in primary water. For example, the present study gives precise values of damage depth for alloy 600 and alloy 718 which may be henceforth used for modeling IGSCC processes.

\section{Acknowledgements}

The authors would like to thank Claude Armand for his helpful contributions to SIMS analysis. They would also like to acknowledge the AREVA Group for its financial support.

\section{References}

[1] M.T. Miglin, H.A. Domian, Microstructure and stress corrosion resistance of alloys X750, 718 and A286 in light water reactor environments, J. Mater. Eng. 9 (1987) 113-132.

[2] R.H. Jones, S.M. Bruemmer, Environment-induced crack growth processes in nickel-base alloys, in: Proceedings of the First International Conference on Environment-Induced Cracking of Metals, October 2-7, Kohler, Wisconsin, 1988, pp. 287-310.

[3] M.O. Speidel, R. Magdowski, Stress corrosion cracking of nickel-base alloys in high temperature water, in: Proceedings of the Sixth International Symposium on Environmental Degradation of Materials in Nuclear Power Systems - Water Reactors, August 1-5, San Diego, California, 1993, pp. 361-376.

[4] G.S. Was, Grain-boundary chemistry and intergranular fracture in austenitic nickel base alloys: a review, Corrosion 46 (1990) 319-330.

[5] R.B. Rebak, Z. Szklarska-Smialowska, The mechanism of stress corrosion cracking of alloy 600 in high temperature water, Corros. Sci. 38 (1996) 971988.
[6] E. Andrieu, P. Pieraggi, Oxidation-deformation interactions and effect of environment in the crack growth resistance of $\mathrm{Ni}$-base superalloys, in: T.Magnin, J.M. Gras, les Editions de Physiques (Eds.), Proceedings of CorrosionDeformation Interactions 1996, Nice, France, 1996, pp. 294-304.

[7] G.S. Was, D.J. Paraventi, J.L. Hertzberg, Mechanism of environmentallyenhanced deformation and intergranular cracking of $\mathrm{Ni}-16 \mathrm{Cr}-9 \mathrm{Fe}$ ", in: $\mathrm{T}$ Magnin, J.M. Gras, les Editions de Physiques (Eds.), Proceedings of CorrosionDeformation Interactions 1996, Nice, France, 1996, pp. 410-420.

[8] J. Chêne, A.M. Brass, Role of temperature and strain rate on the hydrogeninduced intergranular rupture in Alloy 600, Metall. Mater. Trans. A 35 (2004) 457-464.

[9] T. Magnin, F. Foct, O. De Bouvier, Hydrogen effect on PWRSCC mechanisms in monocrystalline and polycrystalline alloy 600, in: Proceedings of the ninth International Symposium on Environmental Degradation of Materials in Nuclear Power Systems - Water Reactors, August 1999, Newport Beach, California, 1999, pp. 27-40.

[10] P.M. Scott, M. Le Calvar, Some possible mechanisms of intergranular stress corrosion cracking of alloy 600 in PWR primary water, in: Proceedings of the Sixth International Symposium on Environmental Degradation of Materials in Nuclear Power Systems - Water Reactors, August 1-5, San Diego, California, 1993, pp. 657-665

[11] R.C. Newman, T.S. Gendron, P. M. Scott, Internal oxidation and embrittlement of alloy 600, in: Proceedings of the Ninth International Symposium on Environmental Degradation of Materials in Nuclear Power Systems - Water Reactors, August 1999, Newport Beach, California, 1999, pp. 79-93.

[12] P.M. Scott, An overview of internal oxidation as a possible explanation of intergranular stress corrosion cracking of alloy 600 in PWRS, in: Proceedings of the Ninth International Symposium on Environmental Degradation of Materials in Nuclear Power Systems - Water Reactors, 1999, pp. 3-12.

[13] P. Combrade, P.M. Scott, M. Foucault, E. Andrieu, P. Marcus, Oxidation of $\mathrm{Ni}$ base alloys in PWR water: oxide layers and associated damage to the base metal, in: Proceeding of 12th International Symposium on Environmental Degradation of Materials in Nuclear Power System - Water Reactors, August 14-18, Salt Lake City, Utah, 2005, pp. 883-890.

[14] C. Soustelle, M. Foucault, P. Combrade, K. Wolski, T. Magnin, PWSCC of alloy 600: a parametric study of surface film effects, in: Proceedings of the Ninth International Symposium on Environmental Degradation of Materials in Nuclear Power Systems - Water Reactors, August 1999, Newport Beach, California, 1999, pp. 105-113.

[15] J. Panter, M. Foucault, P. Combrade, B. Viguier, E. Andrieu, Surface Layers on Alloys 600 and 690 in PWR Primary Water: Possible Influence on Stress Corrosion Cracking Initiation, Corrosion/2002, Paper No. 02519, Houston, TX, NACE, 2002.

[16] J. Panter, B. Viguier, J.M. Cloué, M. Foucault, P. Combrade, E. Andrieu, Influence of oxide films on primary water stress corrosion cracking initiation of alloy 600, J. Nucl. Mater. 348 (2006) 213-221.

[17] F. Carette, M.C. Lafont, G. Chatainier, L. Guinard, B. Pieraggi, Analysis and TEM examination of corrosion scales grown on alloy 690 exposed to pressurized water at $325^{\circ} \mathrm{C}$, Surf. Interface Anal. 34 (2002) 135-138.

[18] F. Delabrouille, B. Viguier, L. Legras, E. Andrieu, Effect of the chromium content on the corrosion of nickel based alloys in primary water of pressurized nuclear reactors, in: G.J. Tatlock, H.E. Evans (Eds.), Proceedings of the Sixth International Conference on the Microscopy of Oxidation, April 4-6, Birmingham, UK, 2005, pp. 115-120

[19] L.E. Thomas, S.M. Bruemmer, High-Resolution Characterization of Intergranular Attack and Stress Corrosion Cracking of Alloy 600 in HighTemperature Primary Water, Corrosion 56 NACE, 2000.

[20] S. Lozano-Perez, J.M. Titchmarsh, TEM investigations of intergranular stress corrosion cracking in austenitic alloys in PWR environmental conditions, Mater. High Temp. 20 (2003) 573-579.

[21] M. Sennour, P. Laghoutaris, C. Guerre, R. Molins, Advanced TEM characterisation of stress corrosion cracking of Alloy 600 in pressurized water reactor primary water environment, J. Nucl. Mater. 393 (2009) $254-266$. 
[22] M. Sennour, L. Marchetti, F. Martin, S. Perrin, R. Molins, M. Pijolat, A detailed TEM and SEM study of Ni-base alloys oxide scales formed in primary conditions of pressurized water reactor, J. Nucl. Mater. 402 (2010) 147-156.

[23] A. Machet, A. Galtayries, S. Zanna, L. Klein, V. Maurice, P. Jolivet, M. Foucault, P. Combrade, P. Scott, P. Marcus, XPS and STM study of the growth and structure of passive films in high temperature water on a nickel-base alloy, Electrochim. Acta 49 (2004) 3957-3964.

[24] Z. Szklarska-Smialowska, W.-K. Lai, Z. Xia, Oxide films formed on alloy 600 in lithiated water at 25 to $350^{\circ} \mathrm{C}$, Corrosion 46 (1990) 853-860

[25] O. Brucelle, Etude de l'effet de la microstructure sur la résistance à la corrosion sous contrainte en milieu primaire R.E.P. de l'alliage 718, PhD Thesis, INPT, Toulouse, France, 2001.

[26] J. Deleume, C. Armand, J.M. Cloué, E. Andrieu, On the use of Ni-Fe-Cr ternary alloys to investigate the consequences of PWR primary water oxidation, in: Proceedings of 13th International Conference On Environmental Degradation of Materials in Nuclear Power Systems, August 19-23, Whistler, British Columbia, Canada, 2007.

[27] B. Ter-Ovanessian, J. Deleume, J.M. Cloué, E. Andrieu, Kinetic study of the low temperature internal oxidation of nickel based model alloys exposed to primary water, Mater. Sci. Forum 595-598 (2008) 449-462.

[28] S.M. Payne, P. Mc Intyre, Influence of grain boundary microstructure on susceptibility of alloy 600 to intergranular attack and stress corrosion cracking, Corrosion 44 (1988) 314-319.

[29] V. Garat, O. Brucelle, J.M. Cloué, V. Rebeyrolle, D. Monceau, B. Viguier, E. Andrieu, Comparing different methods to determine the intergranular oxidation damage on a nickel based superalloy, Mater. Sci. Forum 461-464 (2004) 537-544

[30] J. Deleume, Facteurs métallurgiques et mécaniques contrôlant l'amorçage de défauts de corrosion sous contrainte dans l'alliage 718 en milieu primaire des réacteurs à eau sous pression PhD Thesis, INPT, Toulouse, France, 2007.

[31] S. Lozano-Perez, N. Ni, K. Kruska, C. Grovenor, T. Terachi, T. Yamada, Characterizing environmental degradation in PWRs by 3D FIB sequential sectioning, in: Proceedings of the 15th International Symposium on Environmental Degradation of Materials in Nuclear Power Systems - Water Reactors, August 7-11, Colorado Springs, Colorado, 2011, pp. 993-1004.

[32] C. Guerre, P. Laghoutaris, J. Chêne, L. Marchetti, R. Molins, C. Duhamel, M. Sennour, Stress corrosion cracking of alloy 600 in PWR primary water: influence of chromium, hydrogen and oxygen diffusion, in: Proceedings of the 15th International Symposium on Environmental Degradation of Materials in Nuclear Power Systems - Water Reactors, August 7-11, Colorado Springs, Colorado, 2011, pp. 1477-1488.

[33] P. Laghoutaris, Corrosion sous contrainte de l'alliage 600 en milieu primaire des réacteurs à eau sous pression: Apport à la compréhension des mécanismes, PhD Thesis, ENSMP, Paris, France, 2009.

[34] Y. Shen, P.G. Shewmon, Intergranular stress corrosion cracking of alloy 600 and X-750 in high temperature deaerated water/steam, Metall. Trans. A 22 (1991) $1857-1864$.

[35] D.A. Woodford, R.H. Bricknell, Embrittlement of high temperature alloys by oxygen, in: C.L., Briant, S.K. Banerji (Eds.), Treatise on Materials Science and Technology, vol. 25, Academic Press, 1983, pp. 157-199. 